\title{
EL PERFIL ECONÓMICO DE LA ELITE DE BUENOS AIRES EN LAS DÉCADAS CENTRALES DEL SIGLO XIX
}

ROY HORA Universidad de San Andrés (CONICET) ${ }^{\mathrm{a}}$

\begin{abstract}
RESUMEN
Tradicionalmente se ha afirmado que los grandes terratenientes dominaron el estrato superior de la elite económica argentina en el medio siglo que sucedió a la emancipación. Según esta versión, la crisis de independencia obligó a la elite colonial a desplazar sus negocios desde el comercio hacia la actividad rural, que pronto se convirtió en la base de las principales fortunas del país. A partir de un análisis de los inventarios sucesorios de los de los mayores contribuyentese de Buenos Aires para fines de década de 1830, este trabajo sugiere que, lejos de limitarse a invertir en el sector rural, una parte importante de los grandes capitalistas de mediados del siglo XIX incursionaron en distintas esferas de actividad. El trabajo sugiere que la diversificación de activos fue resultado de los esfuerzos de los capitalistas rioplatenses para enfrentar la inestabilidad económica y política que caracterizó a esas décadas.
\end{abstract}

Palabras clave: terratenientes, Buenos Aires, siglo XIX, capitalistas, patrones de inversión

\footnotetext{
a Departamento de Humanidades. Vito Dumas 284, Victoria (B1644BID). Pcia. de Buenos Aires, Argentina. Tel.: 00541147257000 int. 7219. E-mail: rhora@udesa.edu.ar.
} 


\begin{abstract}
It has often been argued that large landowners formed the core of the Buenos Aires' economic elite during the first half of the nineteenth century. According to this interpretation, the crisis of independence forced the colonial wealthiest capitalists to move from commerce to ranching, which soon emerged as the elite's major source of income. The evidence produced in this article suggests that this interpretation requires revision. Analysis of sucesiones (probate records) for a sample of fifty of Buenos Aires' largest capitalists of the central decades of the XIXth century indicates that, rather than concentrating on rural production, wealthy porteños sought to diversify their assets. This article suggests that this pattern on investment emerged as a result of businessmen's attempts to cope with economic and political instability.
\end{abstract}

Key words: landowners, Buenos Aires, capitalists, patterns of investment, XIX century

JEL Classification: N56, N86.

\title{
1. INTRODUCCIÓN
}

El estudio de las elites económicas republicanas del Río de la Plata comenzó a cobrar forma madura hace más de cuatro décadas, gracias a las contribuciones de Tulio Halperin Donghi. En un ensayo ya clásico dado a conocer en 1963, este autor afirmó que la revolución de independencia y el libre comercio crearon las condiciones que hicieron posible la emergencia y consolidación de un poderoso grupo de grandes terratenientes que en el curso de unos pocos años se constituyó en el sector dominante de la sociedad porteña. Hasta entonces, los intereses de la elite económica de Buenos Aires habían sido eminentemente mercantiles, y giraban en torno al tráfico entre los puertos españoles y europeos y los grandes centros mineros del Alto Perú (del que desde mediados del siglo XVIII Buenos Aires constituía el nexo principal). Desde 1810, las guerras de independencia y la apertura al comercio libre sometieron este escenario a intensas tensiones. Los grandes comerciantes coloniales vieron derrumbarse sus fortunas bajo el triple peso de la crisis del orden mercantilista español, las duras exigencias que trajo consigo la apertura al mundo atlántico y la intensa presión recaudadora del belicoso Estado independiente. Empero, algunos miembros de este grupo lograron sobrevivir a los grandes cataclismos del período, y en el curso de unos pocos años reemergieron, junto a otros capitalistas de diversos orígenes, como parte fundamental de la nueva elite económica republicana. Ello fue posible gracias a 
que en las dos o tres décadas que sucedieron a 1810 los mercaderes coloniales comenzaron a girar capital desde el comercio hacia la producción rural para la exportación, la actividad que ganó mayor dinamismo gracias a la liberalización del comercio exterior. El arribo de mercaderes del Atlántico norte (en su mayoría británicos), con estrechos contactos con los centros mundiales de la Revolución Industrial, contribuyó al desplazamiento de los comerciantes nativos de la esfera de la circulación, reforzando de esta manera el proceso de agrarización de las bases económicas de la elite. En el curso de un par de décadas, pues, se definieron los contornos de la elite terrateniente que constituyó por más de un siglo el segmento más poderoso de las clases propietarias argentinas ${ }^{1}$.

En un trabajo publicado en 1976, Jonathan Brown objetó algunos aspectos de esta interpretación. Este historiador argumentó que si bien los mercaderes nativos del período independiente temprano debieron ceder posiciones en el comercio de importación-exportación que creció al calor de la apertura al comercio atlántico, de todas maneras lograron mantener bajo su control una amplia gama de actividades, en particular en el comercio interno y el transporte de mercancías. Para hacer negocios en el Río de la Plata, afirmó Brown, los hombres llegados del Atlántico Norte debieron apoyarse en una estructura de comercialización interna dominada por comerciantes nativos (tanto criollos como españoles asentados de tiempo atrás en la región) ${ }^{2}$. El énfasis en la capacidad de los mercaderes nativos para adaptarse al nuevo escenario surgido luego de la ruptura con España, sin embargo, no fue obstáculo para que, en su principal contribución a la historiografía sobre el período, Brown suscribiera enfáticamente la visión que señalaba que el vuelco de estos empresarios hacia la producción rural había sido a la vez profundo y veloz. Y a pesar de que ofreció estimaciones más modestas (y a la vez más precisas) sobre la rentabilidad de la actividad ganadera que las que eran corrientes hasta entonces, de todos modos terminó haciendo suyo el punto de vista que señalaba que desde la década de 1820 la producción rural había conformado la gran fuente de ingresos de la nueva elite socioeconómica criolla ${ }^{3}$.

\footnotetext{
1 Halperin Donghi (1963 y 1972). Para un análisis de la contribución de Halperin Donghi, véase Fradkin (1997).

2 Brown (1976), pp. 605-29. En un estudio menos ambicioso, pero igualmente revelador, Robinson sugirió que la "presión de la competencia británica» no logró desplazar del todo a los comerciantes de origen español o criollo, que en la segunda mitad de la década de 1820 constituían una parte sustancial de la comunidad de comerciantes mayoristas de Buenos Aires. Véase Robinson (1979), pp. 120-6. Carlos Marichal (1986), pp. 145-151, ofrece argumentos que relativizan la importancia de la penetración británica en América Latina. Consúltense también los trabajos de D. C. M. Platt (1972 y 1986).

3 Brown (1979).
} 
De este modo, el agudo estudio de Brown, aunque innovador en muchos puntos, finalmente terminó corroborando la interpretación que concibe a la elite socioeconómica porteña como un empresariado cuya cumbre adquirió un neto perfil terrateniente en las décadas que sucedieron a la ruptura con España. Aunque fundada en una multiplicidad de fuentes, esta interpretación ganó sustento gracias a numerosos estudios que han demostrado que la inversión en el sector agropecuario se volvió habitual entre los principales capitalistas porteños del período independiente. La importancia de esta comprobación se advierte cuando recordamos que durante la era colonial los miembros de la elite económica siempre se habían mostrado renuentes a invertir en emprendimientos productivos en el sector rural, y que los estancieros de ese tiempo ocupaban un lugar subordinado en la jerarquía de la riqueza y el poder ${ }^{4}$. La débil vinculación entre la elite colonial y la tierra hace que el énfasis en la inversión agraria que se advierte luego de 1810 resulte especialmente significativo. Es importante señalar, sin embargo, que la constatación de este nuevo énfasis en la inversión rural hasta el momento no ha sido acompañado por una evaluación precisa acerca de la importancia de estas inversiones rurales respecto del patrimonio extra-agrario de los hombres de negocios del período independiente temprano. Al concentrar su atención en los aspectos más novedosos del proceso de cambio económico que tuvo lugar tras la independencia, los autores enrolados en esta corriente de interpretación ignoraron las estrategias que los capitalistas porteños pusieron en práctica para sostener (o reforzar) sus posiciones en otros terrenos, y más bien tendieron a afirmar que los empresarios urbanos que invirtieron en el sector rural se especializaron en esta nueva actividad, dejando completamente de lado los negocios en los que habían incursionado en el pasado. Quienes suscriben estas hipótesis han partido de la premisa de que la rentabilidad de la inversión rural era más elevada, y por tanto más atractiva, que la que predominaba en otros sectores de la economía. Sin embargo, el análisis de este punto, que inevitablemente obliga a un estudio de rentabilidad comparada, no ha sido explorado en todas sus implicancias. En consecuencia, lejos de ofrecer una imagen precisa del giro de los grandes capitalistas hacia la inversión rural, nos encontramos ante una visión que, aunque extendida, todavía presenta algunas facetas desconocidas.

No sorprende, por tanto, que en los últimos años algunos aspectos de esta interpretación hayan sido objeto de debate. Desde la perspectiva que nos interesa explorar en este trabajo, resulta pertinente señalar dos de los temas en revisión. El primero se refiere al lugar de los grandes

\footnotetext{
${ }^{4}$ Socolow (1991). Los estancieros tardocoloniales eran, según una feliz expresión de Carlos Mayo, «landed but not powerful». Véase Mayo (1991).
} 
propietarios en la sociedad rural, y por extensión, a su contribución a la generación del excedente agrario y a la expansión de la economía de exportación. Tradicionalmente se afirmó que la gran estancia ganadera nacida tras la independencia constituyó el único impulsor del crecimiento de la producción rural en la pampa en la primera mitad del siglo XIX. Algunos trabajos recientes, sin embargo, han demostrado que esta hipótesis, que describe a la sociedad rural como un mundo socialmente muy polarizado (compuesto en lo esencial por trabajadores sin tierra - gauchos - y grandes estancieros) es desmentida por la evidencia histórica disponible. Diversos estudios de historia demográfica han puesto de manifiesto que una miríada de pequeños y medianos productores, muchos de ellos dueños de ganado pero también titulares de tierra o de derechos sobre el suelo, desempeñaron un papel igualmente decisivo en el proceso de expansión de la producción y las exportaciones rurales de la región. En algunos aspectos, este crecimiento guarda continuidad con el que tuvo lugar en la segunda mitad del siglo XVIII, al calor de la gradual liberalización del comercio atlántico que signó a la era borbónica (una etapa en el cual, como sabemos, el gran capital urbano o mercantil no desempeñaba un papel relevante en la campaña). El hecho de que la expansión de la producción agraria post-independiente haya tenido lugar en un marco signado por la abundancia de tierra y la escasez de fuerza de trabajo sugiere que, como en otras sociedades de frontera, y a pesar de la indudable expansión que entonces experimentó la gran propiedad terrateniente, muchos miembros de las clases subalternas continuaron disfrutando de un importante grado de independencia social y productiva. En efecto, gracias a su peso demográfico y su control sobre recursos, las clases subalternas rurales desempeñaron un papel relevante como impulsores del crecimiento de la economía de exportación. En síntesis, el ingreso más pleno de nuevos sujetos subalternos dentro del campo de visibilidad de la historiografía rural rioplatense ha permitido calibrar mejor la importancia de los grandes propietarios. Antes que únicos motores del proceso de crecimiento agrario que cobró fuerza tras la ruptura con España, éstos ahora aparecen como protagonistas de una obra que involucra una multiplicidad de actores de segunda importancia, que considerados en conjunto resultan tanto o más relevantes que los grandes terratenientes ${ }^{5}$.

En segundo lugar, al desplazar a los grandes hacendados del lugar de únicos motores de la expansión ganadera postindependiente, los estu-

5 Juan Carlos Garavaglia (1999a); Gelman (1998). La importancia de este fenómeno ya había sido percibida por Brown (1979). Para una discusión, véase Míguez (2000). Un análisis reciente sobre este cambio historiográfico en Ricardo D. Salvatore y Carlos Newland (2003). 
dios recientes han abierto un camino que permite encarar exploraciones más complejas sobre las estrategias de inversión de los sectores más poderosos del empresariado de ese tiempo. En los últimos años, algunos autores han señalado que los nuevos propietarios territoriales surgidos tras la independencia estuvieron lejos de abandonar completamente sus emprendimientos mercantiles ${ }^{6}$. Trabajos recientes basados en el análisis de inventarios judiciales - una fuente muy confiable para el estudio de los patrimonios de los sectores propietarios en el siglo XIX - han mostrado que el vuelco hacia la inversión rural entre los mayores capitalistas de Buenos Aires parece haber sido menos marcado (y menos irreversible) de lo que muchas veces se ha afirmado. En un estudio innovador, basado en el análisis de las fortunas de un conjunto de trece grandes capitalistas con fuertes intereses rurales fallecidos entre 1820 y 1850 , Juan Carlos Garavaglia ha sugerido que el patrón de inversión dominante entre los grandes empresarios de ese período se caracterizaba por la inversión simultánea en distintos terrenos de actividad. Según este autor, algo menos de la mitad del patrimonio total de los estancieros de su muestra se hallaba colocado en empresas agropecuarias. Además de sus inversiones rústicas, estos capitalistas incursionaban en esferas a las que la elite económica habían prestado atención relativamente marginal antes de 1810: renta urbana, negocios financieros, etc. ${ }^{7}$. Algunos estudios de caso sobre grandes propietarios rurales del período dados a conocer en los últimos años confirman, a grandes rasgos, este panora$\mathrm{ma}^{8}$. Por su parte, María Alejandra Irigoin ha sugerido que los mercaderes también adoptaron estrategias que apuntaban a la diversificación, y que la inversión en el sector rural fue una conducta habitual entre los integrantes de este grupo ${ }^{9}$.

Un artículo reciente de Jorge Gelman y Daniel Santilli, basado en el análisis de los registros de la Contribución Directa de 1839, aporta elementos que confirman algunas de estas hipótesis, pero a la vez las integra en un panorama que vuelve a presentar una imagen de conjunto que enfatiza los motivos centrales de la visión tradicional. En particular, señala que el giro hacia la inversión rural entre los capitalistas de la primera mitad del siglo XIX fue tan intenso y tan veloz como en su momento señaló Halperin Donghi. Según estiman sus autores, para fines de la década de 1830 los 28 mayores contribuyentes de Buenos Aires poseía inversiones rurales por un valor equivalente, en promedio, a cerca de las tres cuartas partes de sus activos totales. Los hombres más acaudalados

\footnotetext{
${ }^{6}$ Halperin Donghi (1995).

7 Garavaglia (1999b).

8 Banzato (2002); Hora (2003, 2005a y 2005b).

9 Irigoin (2000).
} 
de Buenos Aires también contaban con inversiones en inmuebles urbanos por valor de un quinto de su patrimonio. El estudio señala, asimismo, que estos grandes empresarios con intereses en la ciudad pero con una clara vocación rural convivían con otros, en general menos poderosos, cuyas fortunas se caracterizaban por una mayor especialización, ya sea en sentido urbano o rural. Finalmente, hacen notar la existencia de otro grupo, integrado en gran parte por extranjeros, que dominaba el comercio de importación y exportación. Estos mercaderes, que constituían el principal nexo entre la economía rural y los mercados internacionales, conformaban la fracción más especializada de la clase capitalista rioplatense. Visto en conjunto, el panorama que resulta de esta exploración sugiere que el proceso de ruralización de las bases de poder económico de la elite criolla se había completado en sus rasgos esenciales mucho antes del derrocamiento de Juan Manuel de Rosas en $1852^{10}$.

Si bien la fuente que Gelman y Santilli utilizan resulta algo más confiable que otras estimaciones fiscales previas, de todas maneras adolece de importantes deficiencias, que en definitiva afectan su utilidad para avanzar en la comprensión de algunos aspectos decisivos de la historia del gran empresariado pampeano. En primer lugar, la Contribución Directa no ofrece información sobre las tenencias en dinero y los activos líquidos, y subestima sin duda alguna la importancia de los créditos en giro y el capital mercantil. En consecuencia, de la lectura de sus listas surge una visión simplificada del patrimonio y de las estrategias de inversión de los hombres de fortuna de Buenos Aires, que otras fuentes nos muestran muy activos en los negocios mercantiles y financieros en esa era de crédito prebancario. Así, por ejemplo, el poderoso Nicolás Anchorena, que en los registros de Contribución Directa de 1839 aparece antes que nada como un gran estanciero (con activos rurales por más del 70 por cien de su fortuna), fue, según nos indica su inventario sucesorio, algo más que un terrateniente, puesto que dejó al morir en 1856 créditos y efectivo por valor de un tercio, si no más, de su patrimonio total, a la vez que propiedad urbana por una cifra similar ${ }^{11}$.

No menos importante, la calidad de las valuaciones del fisco resulta inadecuada para deducir a partir de ellas los rasgos centrales de una fortuna. Parte del problema se relaciona con las peculiares circunstancias en las que fue levantado el censo de 1839 (guerra civil e internacional, bloqueo del puerto, paralización de la actividad exportadora), que trajeron como consecuencia bruscas alteraciones de precios ${ }^{12}$. En ese año,

\footnotetext{
10 Gelman y Santilli (2004).

11 Hora (2005a), pp. 594-6.

12 En 1839, el Estado rosista enfrentaba la agresión de una fuerza naval francesa, que cerró el puerto de Buenos Aires al comercio internacional y ahogó las finanzas públicas. La
} 
los precios de los bienes sujetos a estimación fiscal se derrumbaron, ubicándose muy por debajo de las cotizaciones que alcanzaban antes o después de esa emergencia. Ello ayuda a explicar el hecho de que el valor total de los bienes sujetos a tributación fuese estimado en una cifra similar a la obtenida por la contribución directa de 1825. Aun cuando en el lapso de esos tres lustros la economía bonaerense experimentó una marcada expansión (productiva, demográfica, territorial), y a pesar del mayor empeño puesto de manifiesto por los recaudadores de 1839 , los resultados fiscales de esta valuación se revelan decepcionantes, sin duda por el bajo precio atribuido a los bienes sujetos a imposición.

Por otra parte, esta baja, y su traducción en las estimaciones fiscales, no parece haber sido uniforme. Gelman y Santilli ofrecen algunas evidencias que sugieren que en ese momento el precio que el Estado atribuyó al ganado mayor no estaba alejado de los precios de mercado de estos semovientes ${ }^{13}$. Empero, no proceden del mismo modo con los inmuebles (urbanos y rurales), que constituyen el otro gran ítem sujeto a tributación. Como tendremos oportunidad de observar más adelante, las evidencias reunidas en este trabajo a partir de los precios de tasaciones sucesorias de esos mismos años indican que éstos fueron estimados bien por debajo de su precio de mercado. Al actuar de esta manera, el gobierno de Rosas continuaba una arraigada tradición fiscal, de origen colonial, que hacía pesar el financiamiento del Estado con mayor intensidad sobre los semovientes (y en general la producción agropecuaria) que sobre los inmuebles (una costumbre que aún perdura en la actualidad, por ejemplo, en las marcadas diferencias entre tasaciones fiscales y precios de mercado para la propiedad inmueble y otros bienes sujetos a tributación como los automotores) ${ }^{14}$. La consecuencia es doble: el tamaño de estas fortunas aparece subestimado y, a la vez, se nos ofrece una visión distorsionada del peso relativo de sus principales componentes. En rigor, la imagen global que resulta de la Contribución Directa de 1839 no sólo disminuye el valor de los activos de los mayo-

necesidad de dotarse de recursos con los que afrontar esta agresión imperialista, que pronto encontró aliados locales que la acompañaron, lanzó al fisco en la cruzada recaudadora que dio origen a la revaluación de 1839. Sobre la inestabilidad de los precios relativos en ese período, véase Barba (1999) e Irigoin (2000).

13 El carácter de «equivalente general» de los vacunos y otros animales mayores, típico de una economía de exportación muy especializada en estos productos, debe haberse acentuado como consecuencia de la veloz pérdida de valor que el papel moneda sufrió a lo largo de ese año de intensa inflación. Ello sin duda ayuda a explicar la correspondencia entre precios de tasación y precios de mercado del ganado.

${ }^{14}$ Las estimaciones fiscales del valor de los inmuebles se habían mantenido deprimidas desde el período colonial, por lo que un incremento sustantivo de la valuación, que las colocara más cerca de sus precios de mercado, seguramente amenazaba despertar la resistencia de los propietarios. 
res capitalistas porteños, sino que también exagera la importancia relativa de los activos ganaderos en desmedro de los inmuebles, las inversiones comerciales y los activos líquidos (créditos y efectivo). Y ello conduce a quienes utilizan esta fuente a sobre-enfatizar la orientación rural de la elite.

A pesar de estas limitaciones, es importante señalar que la lista de mayores contribuyentes compilada por Gelman y Santilli constituye un aporte invalorable. Representa el primer esfuerzo sistemático destinado a explorar quiénes se ubicaban en los estratos superiores de la elite económica de Buenos Aires a mediados del siglo XIX, y qué rasgos poseían sus fortunas. De aquí en adelante, todos los estudios sobre los grupos económicamente predominantes -y entre ellos el que aquí ensayaremos-, no pueden sino partir de las evidencias ofrecidas por este esfuerzo pionero de análisis y cuantificación. Para avanzar en la compresión de las características de la elite económica, sin embargo, es preciso analizar este universo con mayor detalle. Este objetivo no puede alcanzarse sin complementar y cotejar la información que surge de las fuentes fiscales con las evidencias ofrecidas por fuentes más precisas, dentro de las cuales los inventarios sucesorios resultan irreemplazables. La utilidad de estas fuentes ha sido repetidamente constatada por todos los investigadores que han recurrido a ellas ${ }^{15}$. Su confiabilidad se vincula directamente con la ausencia de presión fiscal sobre la transmisión gratuita de bienes durante este período, por lo que el ocultamiento patrimonial, tan común en tiempos más recientes (en los que la costumbre de evadir o eludir al fisco se ha convertido en segunda naturaleza para los argentinos) era entonces prácticamente inexistente.

Conviene señalar, de todas maneras, las tres mayores limitaciones de los inventarios sucesorios para el estudio de los hombres de fortuna del siglo XIX. En primer lugar, ellos miden mejor la propiedad que el ingreso y, dentro de aquél, nos permiten estimar mejor el valor de los activos que poseen formas físicas tangibles que las que remiten a destrezas o vinculaciones personales o a posiciones en el mercado que se encuentran, en alguna medida, incorporados a la persona de su propietario. Así, por ejemplo, esta fuente capta con mayor precisión el valor de un inmueble o una estancia que el de una casa comercial (o, en tiempos más recientes, de un estudio profesional) a la que habitualmente sólo reconoce por el monto que representan sus créditos y su inventario, pero sin referencia alguna al valor que significa su posición en el mercado o la reputación y las relaciones de quien la preside. En segundo lugar, estas fuentes nos ofrecen una suerte de radiografía del patrimonio en el

15 Entre otros, Mayo (1995), Amaral (1998), Garavaglia (1999a), Johnson (1999). 
momento del deceso de su propietario ${ }^{16}$. Por tanto, resultan más bien parcas para responder una serie de preguntas cruciales que se refieren a los mecanismos que permitieron la construcción de esas fortunas. En tercer lugar, la información sucesoria guarda un desfasaje, cuya importancia no siempre resulta sencillo determinar, respecto de la etapa en la que su titular se encontraba en su período de mayor actividad. Es habitual que aquellos individuos que han hecho de la adquisición de riqueza su principal objetivo en la vida suelan mantener su interés en la acumulación de dinero hasta el fin de sus días. De todas maneras, resulta conveniente tener presente que nos hallamos ante patrimonios de capitalistas que, al menos en algunos casos, en la última estación de sus vidas pueden haberse visto tentados a privilegiar formas de inversión más seguras que las que dominaron en etapas previas de su ciclo vital. Esta advertencia es particularmente relevante puesto que, como veremos más adelante, la economía rioplatense del período se caracterizaba por niveles particularmente elevados de inestabilidad e incertidumbre, lo que sin duda invitaba a los empresarios a proteger sus activos mediante estrategias de inversión conservadoras.

Teniendo presentes estas precauciones, este trabajo se propone iniciar una exploración de las características del patrimonio de los miembros más prominentes de la elite económica porteña de las décadas centrales del siglo XIX a partir de la consulta de sus inventarios post-mortem. A la luz de la evidencia reunida en las páginas que siguen, el ensayo formula algunas consideraciones sobre la especificidad de los patrones de inversión del grupo económicamente predominante del período postindependiente. Como parte de este ejercicio, también se propone llamar la atención sobre aquellos elementos que distinguen a las fortunas de la elite de los vigentes en etapas previas y posteriores de la trayectoria histórica del país. La especificidad de los patrones de inversión de la elite económica postindependiente —elemento necesario para un estudio más preciso de las transformaciones que la elite económica experimentó a lo largo del siglo XIX- constituye una dimensión que este trabajo se propone resaltar.

Para construir el universo a explorar, el trabajo recurre a la lista de mayores contribuyentes rurales compilada por Gelman y Santilli, y analiza caso por caso la información sucesoria disponible. Es importante

${ }^{16}$ La tradición legal castellana, que a lo largo de este período mantuvo su vigencia en lo que a la legislación sobre herencia se refiere (y que, en líneas generales, se continúa hasta el presente), favorecía una división igualitaria de los bienes entre los hijos legítimos, y limitaba las facultades del legatario para disponer libremente de sus bienes. La fragmentación del patrimonio en el curso de una o dos generaciones fue una consecuencia habitual de este orden legal, que las políticas de recomposición patrimonial puestas en marcha por los integrantes de las nuevas generaciones de una familia no siempre lograba contrarrestar. 
advertir que la utilización de un listado que registra con mayor cuidado el patrimonio inmueble y ganadero puede resultar en la exclusión de algunos capitalistas que no contaban con inversiones de importancia en estos rubros. Estas omisiones potenciales afectan, en primer lugar, a quienes actuaban en la esfera financiera y mercantil, que sin duda aparecerán sub-representados en el universo a analizar. Aún así, todo lo que sabemos sobre la elite porteña del período sugiere que esta muestra resulta razonablemente representativa de la gran riqueza del mayor centro social y económico de la Confederación Argentina.

Conviene señalar, desde un comienzo, que en este trabajo sólo podemos ofrecer información confiable para un número importante pero que está lejos de comprender a la totalidad de los grandes capitalistas porteños. Contamos con información fidedigna para uno de cada tres de los 150 mayores contribuyentes registrados en el censo de 1839 . ¿Quiénes son los excluidos? En primer lugar, aquéllos para los que la información sucesoria no se encuentra disponible o no es lo suficientemente precisa. Entre ellos se destacan, en primer lugar, la mayor parte de los grandes comerciantes extranjeros que dominaban el comercio de importación y exportación, seguramente porque muchos de ellos regresaron a sus países de origen en la etapa final de sus vidas, y en consecuencia no dejaron rastros en los archivos argentinos sobre los que se basa este trabajo. Es preciso tener esta limitación bien presente, de modo de no sacar conclusiones demasiado apresuradas sobre la composición de los grupos económicamente predominantes del período. Igualmente importante, tampoco consideramos a aquellos individuos que, según se desprende de la información cualitativa que está a nuestro alcance, en sus últimos años encararon cambios de envergadura en la estructura de sus patrimonios, desprendiéndose de activos en el sector en el que habían acumulado sus riquezas, y cortando los lazos con la actividad en la que habían construido sus fortunas. En este período, el caso más habitual lo constituye el de aquellos hombres de fortuna que, deseosos de dar mayor seguridad al patrimonio acumulado, se deshicieron de sus empresas agrarias o mercantiles y adquirieron metálico o inmuebles en la ciudad. Los padres de Juan Manuel de Rosas, que en su momento habían poseído importantes propiedades rústicas, pero que terminaron sus vidas como puros rentistas urbanos con una fortuna de unos $\$ \mathrm{~F} 65.000$, sin un metro cuadrado de tierra en la campaña, ofrecen un ejemplo particularmente ilustrativo de este patrón de conducta. Incluir a estas figuras en nuestra muestra hubiese contribuido a ofrecer una imagen distorsionada de los patrones de inversión dominantes en el período. Y aun cuando los numerosos huecos en la información disponible no siempre hacen posible contar con los elementos de juicio que permitan alcanzar una resolución 
enteramente satisfactoria de este problema, siempre que ha sido posible hemos utilizado información cualitativa sobre los rasgos biográficos de los grandes capitalistas para complementar la información de origen sucesorio que constituye el componente fundamental de este trabajo.

Finalmente, es importante formular una última advertencia referida al objeto de este trabajo. Los datos que surgen de una muestra significativa pero relativamente pequeña $(n=50$, que a su vez dividiremos en categorías más acotadas) no aspiran a alcanzar ninguna precisión estadística. El tipo de ejercicio que encaramos se justifica toda vez que este trabajo no se propone alcanzar una conclusión definitiva sobre las características de las mayores fortunas de las décadas que sucedieron a la independencia. Su objeto, más bien, es comprender los patrones de transformación de las grandes fortunas porteñas del siglo XIX. En este sentido, no debe perderse de vista que la calidad de la evidencia recogida, sin duda insuficiente para trazar con precisión el perfil económico de este grupo en un punto determinado del tiempo, se revela menos problemática para contribuir a determinar cuáles fueron los cambios que el patrimonio de la elite económica experimentó en el largo plazo.

\section{LOS CAPITALISTAS PORTEÑOS}

La imagen global que surge de nuestros datos no avala la hipótesis que enfatiza la profundidad y la velocidad de la orientación rural de la elite económica porteña en las décadas que suceden a la revolución de independencia. El cuadro 1 ofrece información sobre la importancia relativa de las inversiones en distintos objetos, dentro y fuera del sector rural, para los 50 grandes capitalistas de Buenos Aires para los que tenemos datos:

\section{CUADRO 1}

50 MAYORES CAPITALISTAS RURALES

DE BUENOS AIRES, SEGÚN CD 1839

\begin{tabular}{|c|c|c|c|c|c|c|}
\hline $\begin{array}{c}\text { Propiedad } \\
\text { Urbana }\end{array}$ & $\begin{array}{c}\text { Chacras } \\
\text { y Quintas }\end{array}$ & $\begin{array}{c}\text { Prop. rural } \\
\text { empresas } \\
\text { agropec. }\end{array}$ & $\begin{array}{c}\text { Créditos } \\
\text { acciones, } \\
\text { activos } \\
\text { comerciales } \\
\text { industriales }\end{array}$ & $\begin{array}{c}\text { Depósitos } \\
\text { bancarios }\end{array}$ & Efectivo & Otros \\
\hline $31,7 \%$ & $4,4 \%$ & $50,3 \%$ & $9,4 \%$ & $2,0 \%$ & $2,3 \%$ & $1,4 \%$ \\
\hline
\end{tabular}


La información que poseemos indica que sólo la mitad del patrimonio total de los mayores empresarios de Buenos Aires de las décadas centrales del siglo XIX se hallaba colocado en empresas rurales. Cerca de un tercio del patrimonio total de estos capitalistas corresponde a propiedad urbana (en casi todos los casos, inmuebles en la ciudad de Buenos Aires, aunque hay también unos pocos en otros centros urbanos menores de esta provincia). En la categoría "chacras y quintas», que deliberadamente hemos separado de la categoría "propiedad rural/empresas agropecuarias», hemos agrupado bienes extra-urbanos cuyo destino principal no resulta posible determinar fehacientemente: en algunos casos éste pudo haber sido residencial y recreativo, en otros productivo, o una combinación de ambos (de hecho, situaciones como ésta advierten sobre las insuperables dificultades que enfrenta todo intento de realizar distinciones demasiado nítidas entre estas categorías, e invita a no perder de vista que estos datos deben interpretarse como simples órdenes de magnitud y como expresiones de tendencias antes que como realidades objetivamente cuantificables). Aunque los bienes comprendidos en esta categoría no pueden considerarse como puramente agrarios, parece razonable argumentar que un porcentaje de ellos (¿un tercio? ¿la mitad?) podría sumarse junto con las empresas rurales. En esta última categoría incluimos tanto al ganado (principal componente de la riqueza rural en ese tiempo) como a la tierra y las mejoras ${ }^{17}$. Queda excluida, en cambio, la inversión en saladeros, graserías y curtiembres que, si bien poco significativa, ubicamos junto con los activos comerciales. Considerando estos elementos, la orientación rural del patrimonio de la elite se acentúa ligeramente, ubicándose ligeramente por encima de la mitad del patrimonio total, pero sin que la base agraria se convierta en excluyente.

Sin embargo, una observación más atenta sugiere la necesidad de realizar ciertas distinciones al interior de este universo. El censo de capitales de 1839 tomó a los empresarios en distintos momentos de su trayectoria vital. Desgraciadamente, no siempre contamos con información precisa sobre la edad de los censados. Sabemos, sin embargo, que mientras que algunos estaban próximos a expirar, otros, en general más jóvenes, se mantuvieron en actividad por varias décadas. De hecho, los inventarios a partir de los cuales surge la información que hemos consignado en el cuadro 1 fueron realizados a lo largo de las cuatro décadas que corren entre mediados de la década de 1830 y mediados de la década de 1870. A lo largo de ese extenso período, el contexto en el que los empresarios incluidos en nuestra muestra debieron desenvolverse experimentó transformaciones

17 En este trabajo no analizamos las características y las modificaciones en el tiempo de la estructura de capital de las empresas agrarias, que por su complejidad requiere un estudio específico. Para un análisis del problema, véase Amaral (1988) y Garavaglia (1999c). 
de consideración. Es razonable suponer que estos cambios tuvieran algún impacto sobre la estructura de las fortunas de aquéllos que se mantuvieron activos por más tiempo (ya porque eran más jóvenes cuando se realizó el censo de 1839, ya porque vivieron vidas más prolongadas). Una imagen de conjunto que no considere este aspecto tiende a opacar ciertas especificidades que no conviene pasar por alto. Por este motivo, resulta conveniente agrupar los inventarios y organizar el análisis en tres momentos distintos, que corresponden a los años rosistas (1834-52), y a períodos sucesivos de alrededor de una década (1853-18644 y 1865-1875). De esta manera, nuestra información aparece distribuida de modo bastante homogéneo (17 inventarios para $1834-52$; 18 para $1853-1864 ; 15$ para 1865-1875) en tres bloques, que corresponden al agitado gobierno de Rosas, a la etapa de crecimiento agrario que sucede a la caída del dictador y, finalmente, al momento de maduración de la economía lanar que se prolonga hasta la presidencia de Avellaneda ${ }^{18}$. Para facilitar las comparaciones, en todos los casos convertimos a moneda metálica (pesos fuertes, o $\$ F$, similares en valor a los pesos moneda nacional de la década de 1880 y a los pesos oro vigente a partir de la sanción de la ley de conversión de 1899) las cotizaciones que figuran en pesos papel en los inventarios y tasaciones. Finalmente, una rápida mirada de conjunto a nuestra información para cualesquiera de estos tres momentos pone de manifiesto la existencia de una clara distinción entre un conjunto de grandes capitalistas, que ocupan los estratos superiores de nuestra muestra, y otro segmento cuyos patrimonios, más simples y modestos, se ubican a considerable distancia de esa cima. Ello invita a analizarlos por separado. Demás está decir que desagregados de esta manera, los datos que surgen de nuestra muestra, ya de por sí relativamente pequeña $(n=50)$, no pretenden alcanzar ninguna forma de precisión estadística. Como ya señalamos, lo que nos interesa es comprobar ciertas regularidades y explorar los patrones de transformación de las grandes fortunas del período.

Consideremos en primer lugar los patrimonios tasados durante el período rosista. El cuadro 2 presenta información sobre la composición de las fortunas de los siete mayores capitalistas de nuestra muestra para los años que corren entre 1834 y 1852 :

18 Es evidente que la confiabilidad del censo de contribuyentes de 1839 para identificar a los mayores capitalistas de Buenos Aires disminuye con el paso de las décadas, aunque no lo suficiente como para que el ejercicio que aquí ensayamos pierda toda su utilidad. La ausencia de un censo de grandes capitalistas para períodos posteriores constituye un obstáculo decisivo para una exploración más sistemática de este universo en la segunda mitad del siglo XIX. De todos modos, la literatura histórica ofrece abundantes testimonios impresionistas que indican que buena parte de los capitalistas que aparecen en el listado de 1839 siguieron ocupando las posiciones más prominentes en la jerarquía de la riqueza de Buenos Aires entrado el último tercio del siglo XIX. 
EL PERFIL ECONÓMICO DE LA ELITE DE BUENOS AIRES EN LAS DÉCADAS CENTRALES..

CUADRO 2

CAPITALISTAS CON PATRIMONIOS SUPERIORES A \$F 100.000 (1834-1852)

$$
(n=7)
$$

\begin{tabular}{|c|c|c|c|c|c|c|c|}
\hline $\begin{array}{c}\text { Propiedad } \\
\text { Urbana }\end{array}$ & $\begin{array}{c}\text { Chacras } \\
\text { y Quintas }\end{array}$ & $\begin{array}{c}\text { Prop. rural } \\
\text { empresas } \\
\text { agropec. }\end{array}$ & $\begin{array}{c}\text { Créditos } \\
\text { acciones, } \\
\text { activos } \\
\text { comerciales } \\
\text { industriales }\end{array}$ & $\begin{array}{c}\text { Depósitos } \\
\text { bancarios }\end{array}$ & Efectivo & Otros & $\begin{array}{c}\text { Promedio } \\
\text { patrimonio }\end{array}$ \\
\hline $48,5 \%$ & $6,2 \%$ & $33,7 \%$ & $6,3 \%$ & $0,1 \%$ & $1,6 \%$ & $3,3 \%$ & $\$ \mathrm{~F} 195.499$ \\
\hline
\end{tabular}

Este universo está integrado Félix de Alzaga, Joaquín Suárez, Francisco Piñeyro, Luis Acuña, Blas Achával, José Insua y Díaz, y Francisco Suárez. Al momento de fallecimiento, estos hombres poseían patrimonios que iban de los $\$ \mathrm{~F} 370.000$ a los $\$ \mathrm{~F} 125.000$, con un promedio cercano a los \$F 200.000 (una cifra que equivale, en moneda de la época, a otros tantos dólares, o a unas 40.000 libras esterlinas). La suma de estos siete patrimonios es igual al valor de los activos totales de los 25 mayores contribuyentes (o de los activos rurales de los 28 mayores contribuyentes) registrados en el censo de 1839. Más que la vastedad de los recursos de estos capitalistas, ello nos está indicando la subestimación que resulta de los datos de la CD. Esta impresión se confirma cuando advertimos que el tamaño de estos patrimonios resulta bastante reducido, puesto que está por debajo de las mayores de la era borbónica en la región ${ }^{19}$. Es cierto que entre estos empresarios no se cuentan algunos de los principales capitalistas de esos tiempos, para los que no contamos con información sucesoria precisa. Si estos fuesen incluidos, sin embargo, el panorama difícilmente sufriría cambios drásticos, puesto que las fortunas de algunos de los más poderosos de ellos (como Juan José de Anchorena) no eran de una escala superior a las que aquí analizamos ${ }^{20}$. Se confirma así que las décadas que sucedieron a la independencia no fueron buenas para los hombres de fortuna porteños. En ese momento, éstos se encontraban a considerable distancia de otras elites americanas cuyos patrimonios, en gran parte agrarios, crecieron a lo largo de la primera mitad del siglo XIX al calor de la expansión de la economía atlántica. Entre la esclavocracia del sur de Estados Unidos, por ejemplo, para mediados de siglo encontramos patrimonios cinco o seis veces superiores a las de los mayores hombres de fortuna de Buenos Aires, que se ubican bien por encima de los $\$ F$ 2.000.000 ${ }^{21}$.

\footnotetext{
19 Socolow (1991), p. 213; Gelman (1996).

20 Hora (2005a), pp. 588-9.

21 Scarborough (2003), pp. 9-17.
} 
Vistos en conjunto, estos siete capitalistas porteños presentan notables similitudes. El primer elemento que salta a la vista es que, salvo en un caso, todos ellos realizaron inversiones rurales muy considerables tras la emancipación (la excepción es Luis Acuña, un comerciante que no dejó bienes en el campo). A diferencia de los integrantes de la elite económica del México o del Perú borbónicos, que invirtieron importantes sumas en la compra de haciendas, los hombres de fortuna del Buenos Aires virreinal siempre se mostraron remisos a invertir en el sector rural ${ }^{22}$. Algunos datos nos permiten comparar ambos momentos, y ofrecer algunas estimaciones sobre la magnitud del vuelco hacia la tierra que se verifica tras la apertura comercial que la emancipación trajo consigo. Según señala un conocido trabajo de Garavaglia, las dos mayores fortunas rurales de los años previos a 1815, pertenecientes a Juan Pablo Ferreira Méndez y Juan de San Martín, se ubicaban en \$ 50.000 y $\$ 36.000$ respectivamente; ningún otro patrimonio agrario colonial alcanzaba los $\$ 25.000^{23}$. Se trata de fortunas modestas, mucho menores que las que encontramos en el período 1835-52. En efecto, en promedio, las inversiones en el campo de los mayores siete capitalistas de nuestra muestra para este último período superan la mayor fortuna de los años virreinales, pues se ubican por encima de los $\$ 60.000$. Y el mayor patrimonio agrario tasado en los años rosistas, perteneciente a Félix de Alzaga, que alcanzaba unos \$185.000, está cerca de cuadruplicar la más importante fortuna rural de los tiempos virreinales.

Estos datos dejan fuera de toda duda que luego de la emancipación se verificó una importante reorientación de los recursos de la elite hacia la inversión rural. Pero aun cuando el tamaño de los patrimonios rústicos se incrementó de modo muy marcado respecto a la era borbónica, acompañando un crecimiento de la escala de las empresas agrarias, conviene tener presente que nos hallamos ante capitalistas cuyos intereses en el sector rural, aunque muy considerables, se encontraban lejos de constituir el único elemento sobre el cual reposaban sus fortunas. De hecho, los activos rurales de estos capitalistas representan una porción significativa pero acotada de sus fortunas (que en ningún caso excedía el 54 por cien del patrimonio total), que mantienen todavía una fuerte orientación urbana, con importantes anclajes en la renta del suelo y, en menor medida, en los negocios financieros y mercantiles.

Las inversiones en bienes raíces en la ciudad constituyen sin duda el elemento más sorprendente de este cuadro, tanto por sus dimensiones

\footnotetext{
22 Socolow (1991), cap. 3.

${ }^{23}$ Garavaglia (1999a), p. 150.
} 
absolutas como porque reflejan una novedad respecto a etapas previas. Este aspecto del problema no ha sido estudiado en todas sus implicancias. En efecto, el notable peso que alcanzan las inversiones en bienes urbanos de los mayores capitalistas de esta muestra supone una marcada acentuación de una forma de inversión que había tenido importancia más acotada para los hombres de fortuna del virreinato. El conocido estudio de Susan Socolow sobre los comerciantes coloniales nos ofrece datos sobre las inversiones urbanas para seis de los mayores capitalistas de la era borbónica (Inchaurregui, Lezica, Ruiz Gaona, Segurola, Tellechea y Zapiola). Estos grandes mercaderes, que en todos los casos dejaron al fallecer fortunas superiores a $\$ 100.000$, contaban con inmuebles en la ciudad por apenas el 21,6 por cien de su patrimonio ${ }^{24}$. De acuerdo con la información disponible, pues, tras la emancipación el peso de las inversiones urbanas del segmento más acaudalado de la elite se multiplicó cerca de 2,5 veces.

Pero si bien el peso de las inversiones urbanas resulta muy acusado, conviene formular dos aclaraciones que ayudan a situar mejor sus dimensiones y su significación (que valen, dicho sea de paso, también para el período colonial). En primer lugar, es preciso tener presente que la relevancia de esas inversiones se ve algo sobreestimado porque en ellas suele incluirse la residencia personal, que en algunos casos representa cerca de un cuarto del valor total de los inmuebles que estos hombres poseían en la ciudad. Este fenómeno no se reproduce con las inversiones rústicas, que en este período pueden calificarse como patrimonio productivo prácticamente en su totalidad. Para esta elite de cultura citadina, y de raíces rurales muy superficiales y recientes, el campo era antes que nada un lugar para valorizar el capital. Aún estamos muy lejos del momento en el que la elite porteña fue ganada por la fiebre ruralista que la llevó a erigir grandes casas y parques de recreo en sus estancias, y a residir allí de modo regular durante los meses del verano ${ }^{25}$.

En segundo lugar, diversos trabajos sugieren que la rentabilidad de la inversión rural era muy superior a la que ofrecían las inversiones de renta en la ciudad (aun cuando esto no siempre se cumplía en el corto y mediano plazo). Distintas estimaciones sobre la rentabilidad de la ganadería porteña del período colocan la tasa de beneficio en un rango que va, según los casos, del 8 por cien al 30 por cien anual, aunque con intensas fluctuaciones ${ }^{26}$. Toda consideración sobre la rentabilidad

\footnotetext{
24 Socolow (1991), p. 215.

25 Hora (2002a), pp. 77-100.

26 Halperin Donghi, haciéndose eco de estimaciones contemporáneas, afirmó que las ganancias podían alcanzar el 30 por cien anual en años buenos. Un estudio de Brown para
} 
agraria también debe tener en cuenta que las formas de asociación entre capitalistas y sujetos económicos más débiles eran habituales, por lo que no siempre los propietarios del suelo o del capital embolsaban la totalidad de los beneficios que generaba una explotación ${ }^{27}$. Hay que recordar que las pérdidas tampoco eran infrecuentes, tanto por condiciones climáticas desfavorables (entre las que se destaca la gran sequía de 1829-32), problemas políticos (como los bloqueos del puerto, la inestabilidad monetaria y legal o las guerras civiles que jalonaron esas décadas) o decisiones empresariales que retrospectivamente se revelaron poco felices. Por estos motivos, las ventajas de contar con inversiones de renta en la ciudad, que rendían regularmente entre un 5 por cien y un 7 por cien anual, se volvía evidente en años malos para la inversión rural. Pues aunque este tipo de colocaciones no resultaba tan rendidora, a cambio ofrecía un ingreso seguro a la vez que buenas perspectivas de valorización en el largo plazo. El hecho de que en el momento del reparto sucesorio de las fortunas que estamos considerando las hijas solteras y las viudas habitualmente recibiesen una parte más que proporcional de su haber en bienes de renta urbana, y muy rara vez en bienes de renta rural (que no ocupaban un lugar de relevancia en las fortunas que estamos analizando), indica a las claras que en este período el arrendamiento urbano era más confiable y más atractivo que el arrendamiento del suelo rural. Es importante tener estos elementos en cuenta, pues la fuente de la que obtenemos nuestros datos suele ofrecernos información sobre personas ya maduras, sin duda poco propensas a realizar inversiones arriesgadas. Y aun cuando este último punto no debiera exagerarse (puesto que en el siglo XIX la muerte podía llamar a la puerta muy temprano, o de forma sorpresiva), parece indudable que la información recogida en los inventarios post-mortem sobreestima, en un grado difícil de determinar, el peso de las inversiones urbanas respecto a etapas previas del ciclo de vida.

Finalmente, la presencia de créditos, activos comerciales y dinero en efectivo, que representan menos de una décima parte de estas fortunas, revela que la actividad mercantil ya no constituía la principal fuente de recursos de la elite. De todas maneras, el hecho de que estos capitalistas poseyeran una quinceava parte de sus activos en la esfera de la circulación está indicando que este terreno todavía constituía una

una estancia de mediados de la década de 1840 estimó una tasa de beneficio del cercana al 20 por cien. Las empresas de los hermanos Anchorena rindieron un 17 por cien anual entre 1822 y 1825 ; en años posteriores, sin embargo, las ganancias no fueron tan elevadas e incluso debieron afrontar pérdidas. Véase Halperin Donghi (1963), p. 35; Brown (1979), pp. 271-76; Hora (2005a), pp. 581-8. Para una discusión del problema, Amaral (1998).

27 Algunos ejemplos en Mateo (1993), Garavaglia (1999 y Hora (2005). 
fuente de oportunidades de inversión. Hay que señalar, también, que es muy probable que estos activos aparezcan subestimados, como consecuencia de la costumbre de tasar el valor de una casa comercial por su inventario y sus créditos sin referencia a su posición en el mercado, así como de las mayores facilidades para distribuir activos líquidos, con o sin el consentimiento de todos los herederos, fuera de la mirada de la justicia.

La evidencia que aquí presentamos confirma que la diversificación de activos parece haber sido una conducta habitual entre los grandes capitalistas de las décadas que sucedieron a la independencia. Sin embargo, ello no debe hacernos perder de vista el hecho de que todo lo que sabemos sobre la historia económica rioplatense de esos años indica que la inversión rural constituía el segmento más dinámico de estas fortunas. No deja de ser significativo, empero, que a pesar de la mayor rentabilidad de la inversión rural, en casi todos los casos el patrimonio productivo urbano de estos capitalistas siguiese siendo superior, o en todo caso similar, al rural. Ello nos está indicando que consideraciones distintas a las referidas a la mera rentabilidad, entre las cuales la seguridad parece especialmente relevante, eran decisivas para estos hombres de negocios. En el Río de la Plata posterior a la independencia, el costo de oportunidad y la tasa de beneficio sectorial no parecen haber sido los únicos elementos a ponderar a la hora de tomar decisiones de inversión. Todo sugiere que estos empresarios diversificaron sus fuentes de inversión no tanto para maximizar sus beneficios como para minimizar riesgos. Ello explica por qué la renta urbana y las actividades mercantiles y crediticias constituían, junto con la inversión agropecuaria, dos de los pilares sobre los cuales se erigían las fortunas de la cumbre de la elite económica de los años rosistas.

$\mathrm{Al}$ volver nuestra atención sobre los propietarios que se encontraban por debajo de este selecto grupo se pone de manifiesto un salto cualitativo, que nos conduce hacia un universo más modesto. De los diez capitalistas fallecidos entre 1835 y 1852 para los que tenemos datos sólo uno de ellos alcanza los $\$ \mathrm{~F} 80.000$; el promedio de estas fortunas se ubica bastante más abajo, en torno a los $\$ F$ 53.600. Lo que es más importante, el descenso en el tamaño del patrimonio es acompañado por una acentuación muy marcada de la especialización, ya sea en sentido urbano o mercantil, ya sea en sentido rural. Por tal motivo, conviene presentar nuestra información desagregada, de acuerdo al peso relativo de las inversiones en el campo o la ciudad. Organizada de esta manera, nos encontramos con dos grupos que se distinguen muy claramente uno de otro, compuesto cada uno por de ellos cinco individuos. La información para aquéllos con inversiones predominantemente urbanas es la siguiente: 


\section{CUADRO 3}

CAPITALISTAS CON INVERSIONES PREDOMINANTEMENTE URBANAS CON PATRIMONIOS INFERIORES A \$F $100.000(1834-52)(n=5)$

\begin{tabular}{|c|c|c|c|c|c|c|c|}
\hline $\begin{array}{c}\text { Propiedad } \\
\text { Urbana }\end{array}$ & $\begin{array}{c}\text { Chacras } \\
\text { y Quintas }\end{array}$ & $\begin{array}{c}\text { Prop. rural } \\
\text { empresas } \\
\text { agropec. }\end{array}$ & $\begin{array}{c}\text { Créditos } \\
\text { acciones, } \\
\text { activos } \\
\text { comerciales } \\
\text { industriales }\end{array}$ & $\begin{array}{c}\text { Depósitos } \\
\text { bancarios }\end{array}$ & Efectivo & Otros & $\begin{array}{c}\text { Promedio } \\
\text { patrimonio }\end{array}$ \\
\hline $65,1 \%$ & $7,4 \%$ & $1 \%$ & $18,4 \%$ & - & $4,0 \%$ & $2,8 \%$ & $\$ \mathrm{~F} 64.362$ \\
\hline
\end{tabular}

Como se advierte, hallamos aquí hombres de fortuna eminentemente urbana, que carecían de vinculación con el mundo rural (sólo uno de ellos cuenta con inversiones en el campo, que de todas maneras apenas representa el 5 por cien de su patrimonio). En este grupo se encuentran Joaquín Belgrano, Juan de Souza Monteiro, Juan Antonio Aguirre, Manuel Pérez del Cerro y Matías Irigoyen. Estos hombres poseían el grueso de sus activos en inmuebles (muchos de ellos de renta) y, en menor medida, en activos comerciales. Todo sugiere que la actividad económica predominante de estos hombres se ha concentrado en la esfera mercantil, y que han girado regularmente los excedentes que obtenían en esta actividad hacia la compra de propiedades urbanas, que al momento de fallecer representa el corazón de sus fortunas.

Volvamos ahora la atención sobre los capitalistas de este mismo rango con activos mayormente rurales. La información sobre los cinco integrantes de este grupo es la siguiente:

\section{CUADRO 4}

CAPITALISTAS CON INVERSIONES PREDOMINANTEMENTE RURALES CON PATRIMONIOS INFERIORES A \$F $100.000(1834-52)(n=5)$

\begin{tabular}{|c|c|c|c|c|c|c|c|}
\hline $\begin{array}{c}\text { Propiedad } \\
\text { Urbana }\end{array}$ & $\begin{array}{c}\text { Chacras } \\
\text { y Quintas }\end{array}$ & $\begin{array}{c}\text { Prop. rural } \\
\text { empresas } \\
\text { agropec. }\end{array}$ & $\begin{array}{c}\text { Créditos } \\
\text { acciones, } \\
\text { activos } \\
\text { comerciales } \\
\text { industriales }\end{array}$ & $\begin{array}{c}\text { Depósitos } \\
\text { bancarios }\end{array}$ & Efectivo & Otros & $\begin{array}{c}\text { Promedio } \\
\text { patrimonio }\end{array}$ \\
\hline $16,7 \%$ & $0,9 \%$ & $80,1 \%$ & $0,3 \%$ & - & $0,2 \%$ & $1,7 \%$ & $\$ \mathrm{~F} 42.788$ \\
\hline
\end{tabular}

Advertimos aquí la otra cara de la especialización a la que hacíamos referencia en los párrafos anteriores. Ignacio Correa, John Miller, Peter Sheridan, Esteban Puddicomb y José Miguens eran empresarios de clara vocación rural (con la excepción parcial del primero, que sólo poseía 
inversiones en el campo por el 48,5 por cien de su fortuna). Los patrimonios de estos hombres se ubican a considerable distancia de los acumulados por los grandes capitalistas de fortunas diversificadas que coronaban la cúspide del empresariado de esos años. Resulta igualmente revelador que sus patrimonios fuesen inferiores a los de los empresarios de orientación predominante urbana que acabamos de analizar. Y si bien la CD subestima el valor de los activos de estos hombres de fortuna rural (les otorga en promedio de apenas unos $\$ F$ 18.400), de todas maneras la diferencia entre la tasación judicial y las fuentes fiscales es significativamente menor que en el caso de los propietarios urbanos de igual rango (43 por cien y 29 por cien, respectivamente). Este dato sugiere que la presión fiscal que el Estado rosista ejerció a través de la Contribución Directa cayó con mayor fuerza sobre la riqueza rural que sobre la urbana. Ello nos indica que las versiones que presentan al rosismo como un gobierno que obró sistemáticamente a favor de los intereses terratenientes, en particular de los más poderosos, simplifican un cuadro bastante más complejo. En lo que se refiere a la presión tributaria directa, el mundo rural no parece haber sido el más favorecido.

¿En qué medida el panorama que describimos para las décadas de 1830 y 1840 se modificó en años posteriores? El cuadro 5 ofrece información sobre la composición del patrimonio de los ocho mayores fortunas de nuestra muestra tasadas en el período 1853-1864. Estos patrimonios se ubican, en todos los casos, por encima de los \$F 200.000.

El primer elemento que salta a la vista es el aumento del tamaño absoluto de los patrimonios tasados en el período cuyo comienzo coincide con la batalla de Caseros. Éstos han crecido en promedio más de dos veces respecto de la etapa anterior. Las ocho mayores fortunas de 1853-1864 (pertenecientes a Luis Dorrego, Pedro J. Vela, Simón Pereyra, Felipe Senillosa, Prudencio Rosas, Eustoquio Díaz Vélez, Vicente Castex, Miguel Riglos y Juan Crisol ) oscilan entre \$F 762.500 y $\$ F$ 214.100, con un promedio ligeramente por debajo del medio millón

CUADRO 5

CAPITALISTAS RURALES CON PATRIMONIOS SUPERIORES A \$F 200.000 $(1853-64)(n=8)$

\begin{tabular}{|c|c|c|c|c|c|c|c|}
\hline $\begin{array}{c}\text { Propiedad } \\
\text { Urbana }\end{array}$ & $\begin{array}{l}\text { Chacras } \\
\text { y Quintas }\end{array}$ & $\begin{array}{c}\text { Prop. rural } \\
\text { empresas } \\
\text { agropec. }\end{array}$ & $\begin{array}{c}\text { Créditos } \\
\text { acciones, } \\
\text { activos } \\
\text { comerciales } \\
\text { industriales }\end{array}$ & $\begin{array}{l}\text { Depósitos } \\
\text { bancarios }\end{array}$ & Efectivo & Otros & $\begin{array}{l}\text { Promedio } \\
\text { patrimonio }\end{array}$ \\
\hline $26,5 \%$ & $4,2 \%$ & $41,1 \%$ & $21,4 \%$ & $2,6 \%$ & $2,6 \%$ & $0,9 \%$ & $\$ F 435.684$ \\
\hline
\end{tabular}


de pesos; la quinta de estas fortunas resulta superior a la mayor de nuestra muestra tasada antes de la caída de Rosas. Ello ofrece un indicador indirecto pero fidedigno acerca del intenso ritmo de crecimiento que la riqueza social experimentó en el período que sucede a la derrota del dictador. Aún cuando nuestro trabajo no se propone captar fenómenos de concentración, la capacidad de los grandes capitalistas para apropiarse de parte de la nueva riqueza acumulada en esos años parece indudable. En estas cifras parece reflejarse el sostenido proceso de crecimiento agrario que tuvo lugar desde fines de la década de 1840, una vez dejadas atrás las consecuencias de la devastadora sequía de 182932, la guerra civil de 1840-41 y de los bloqueos que los puertos de la Confederación sufrieron entre 1838 y 1848. Es importante, sin embargo, no exagerar la prosperidad que la elite porteña alcanzó en ese período de acelerado crecimiento económico, pues ésta siguió siendo relativamente humilde a escala internacional. Si bien las fortunas porteñas eran entonces superiores a las que en esos años se acumulaban en San Pablo (todavía un centro urbano de segundo orden, que aún no había comenzado su despegue como productor de café), se ubican a considerable distancia no sólo de las elites europeas (para entonces en Inglaterra existían fortunas superiores a los \$F 25 millones), sino también de otras clases propietarias hispanoamericanas, que eran desde tiempo atrás bastante más acaudaladas (Pedro Romero de Terreros, el magnate mexicano, había dejado más de $\$ 4$ millones tras su fallecimiento a fines del período colonial) ${ }^{28}$.

En segundo lugar, se advierte una marcada acentuación del peso de la inversión rural, que del 31,2 por cien que registra en 1834-52 ha crecido hasta sobrepasar el 41 por cien del patrimonio total. Este incremento se realiza a costa de la inversión en propiedad urbana, que sufre una notable retracción. La importancia de los activos mercantiles, aún mayor que para las grandes fortunas tasadas antes de 1852, también merece destacarse. Y aunque estamos hablando de patrimonios que siguen siendo sólo parcialmente rurales, la orientación agraria de los sectores más poderosos de la elite parece acentuarse. En las cifras del cuadro 5 se pone de manifiesto la llegada a la cima de la sociedad porteña de un grupo de grandes capitalistas cuyos intereses rústicos, sin desplazar completamente a las inversiones urbanas, se erigen como los más relevantes. Teniendo en cuenta las precauciones que en su momento señalamos respecto al desfasaje entre la fecha de tasación y la historia de construcción de esas fortunas, advertimos aquí un importante hito en la historia del empresariado rural en la pampa.

\footnotetext{
28 Cardoso de Mello (1990), pp. 160-2; Boorstein Couturier (2003).
} 
¿Qué rasgos presentan los patrimonios de los diez capitalistas con fortunas inferiores a los \$F 200.000 tasadas entre 1853 y 1864? Al igual que en el período anterior, también aquí se advierte que las fortunas más pequeñas suelen vincularse a una única actividad. Y, aunque no al mismo ritmo que en el caso de los mayores patrimonios del período, asistimos a un importante incremento en el tamaño de las fortunas de estos ricos de segundo rango, que en promedio ha crecido casi 1,7 veces respecto de los años 1834-52 (el promedio se ubica en $\$ F$ 89.500). De los diez empresarios para los que tenemos datos, dos superan los $\$ F$ 150.000; el resto cuenta con activos que oscilan entre los $\$ F 110.000$ y los $\$ F$ 30.000. Si bien la distancia entre la elite de nuestra muestra y estos capitalistas menos prominentes no se ha cerrado, de todas maneras se advierte que éstos se apropian de parte del incremento de la riqueza social que la expansión de la economía porteña de las décadas centrales del siglo XIX hizo posible. El otro elemento a destacar es que, a diferencia del período anterior, ha crecido notablemente la importancia relativa de los patrimonios rurales, a punto tal que ocho de las diez que consideramos tienen este origen. Sin embargo, las dos mayores fortunas de este grupo (Ladislao Martínez y Bonifacio Huergo) mantienen una acusada orientación urbana. Pero a diferencia de las de igual rango tasadas en los años rosistas, en estas últimas el peso de las inversiones urbanas es menos relevante, y a la vez se incrementa la importancia de los activos rurales. La información sobre estas dos fortunas se aprecia en el siguiente cuadro:

\section{CUADRO 6}

CAPITALISTAS CON INVERSIONES PREDOMINANTEMENTE URBANAS CON PATRIMONIOS INFERIORES A \$F $200.000(1853-64)(n=2)$

\begin{tabular}{|c|c|c|c|c|c|c|c|}
\hline $\begin{array}{c}\text { Propiedad } \\
\text { Urbana }\end{array}$ & $\begin{array}{c}\text { Chacras } \\
\text { y Quintas }\end{array}$ & $\begin{array}{c}\text { Prop. rural } \\
\text { empresas } \\
\text { agropec. }\end{array}$ & $\begin{array}{c}\text { Créditos } \\
\text { acciones, } \\
\text { activos } \\
\text { comerciales } \\
\text { industriales }\end{array}$ & $\begin{array}{c}\text { Depósitos } \\
\text { bancarios }\end{array}$ & Efectivo & Otros & $\begin{array}{c}\text { Promedio } \\
\text { patrimonio }\end{array}$ \\
\hline $49 \%$ & $11,4 \%$ & $16,2 \%$ & $17,6 \%$ & - & $5,9 \%$ & - & $\$ \mathrm{~F} 178.265$ \\
\hline
\end{tabular}

Las ocho fortunas restantes (Antonino Cascallares, Juan M. Silva, Blas Mancebo, Jacinto Machado, José M. Pizarro, Santiago Chiclana, Felipe y Eusebio Miguens), cuyos rasgos se resumen en el cuadro 7, son eminentemente rurales. El aumento del tamaño y de la importancia de las fortunas de base rústica parece estar revelando, una vez superada la crítica década de 1838-48, el impacto del crecimiento de la 
economía de exportación. En todos los casos, estos capitalistas poseían el grueso de sus activos en el campo; alguna propiedad urbana completaba su fortuna.

\section{CUADRO 7}

CAPITALISTAS CON INVERSIONES PREDOMINANTEMENTE RURALES CON PATRIMONIOS INFERIORES A \$F $200.000(1853-64)(n=8)$

\begin{tabular}{|c|c|c|c|c|c|c|c|}
\hline $\begin{array}{c}\text { Propiedad } \\
\text { Urbana }\end{array}$ & $\begin{array}{c}\text { Chacras } \\
\text { y Quintas }\end{array}$ & $\begin{array}{c}\text { Prop. rural } \\
\text { empresas } \\
\text { agropec. }\end{array}$ & $\begin{array}{c}\text { créditos } \\
\text { acciones, } \\
\text { activos } \\
\text { comerciales } \\
\text { industriales }\end{array}$ & $\begin{array}{c}\text { Depósitos } \\
\text { bancarios }\end{array}$ & Efectivo & Otros & $\begin{array}{c}\text { Promedio } \\
\text { patrimonio }\end{array}$ \\
\hline $10,9 \%$ & $2,3 \%$ & $81,8 \%$ & $0,5 \%$ & $3,3 \%$ & $1,2 \%$ & $0,9 \%$ & $\$ \mathrm{~F} 67.388$ \\
\hline
\end{tabular}

Volvamos ahora nuestra atención hacia las fortunas tasadas entre 1865 y 1875. La información para los ocho mayores patrimonios de esos años (Juan Nepomuceno Terrero, Angel Pacheco, Casto Sáenz Valiente, Juan Bautista Peña, Manuel Cobo, Tomás Manuel de Anchorena, Juan Cano, Juan B. Molina), que se recortan claramente del resto de los patrimonios, es la siguiente:

\section{CUADRO 8}

CAPITALISTAS CON PATRIMONIOS SUPERIORES A \$F 750.000 (1865-75)

$$
(n=8)
$$

\begin{tabular}{|c|c|c|c|c|c|c|c|}
\hline $\begin{array}{c}\text { Propiedad } \\
\text { Urbana }\end{array}$ & $\begin{array}{c}\text { Chacras } \\
\text { y Quintas }\end{array}$ & $\begin{array}{c}\text { Prop. rural } \\
\text { empresas } \\
\text { agropec. }\end{array}$ & $\begin{array}{c}\text { Créditos } \\
\text { acciones, } \\
\text { activos } \\
\text { comerciales } \\
\text { industriales }\end{array}$ & $\begin{array}{c}\text { Depósitos } \\
\text { bancarios }\end{array}$ & Efectivo & Otros & $\begin{array}{c}\text { Promedio } \\
\text { patrimonio }\end{array}$ \\
\hline $28,6 \%$ & $3,2 \%$ & $47,8 \%$ & $11,2 \%$ & $5,4 \%$ & $2,7 \%$ & $0,7 \%$ & $\$ \mathrm{~F} 1.187 .747$ \\
\hline
\end{tabular}

Los datos ponen de manifiesto la consolidación de las principales líneas de desarrollo que habíamos tenido oportunidad de señalar cuando analizamos las tasaciones efectuadas durante la etapa 1853-64. Se advierte, en primer lugar, que el aumento del tamaño absoluto de las fortunas de los grandes capitalistas porteños no sólo no se detuvo sino que, durante esos años de creciente madurez de la economía lanar, siguió su 
marcha ascendente con mayor fuerza que en el decenio que sucedió al derrocamiento de Rosas. Al calor de la expansión ovina, las mayores fortunas de esta muestra, que superaban los $\$ F 300.000$ pesos en la década de 1840 , y que se ubicaban por encima del medio millón en la década de 1850, finalmente quebraron la barrera del millón de pesos. La mayor de todas ellas alcanza los \$F 2,3 millones; otras cuatro superan el millón. Si recordamos que en esos tiempos el peso fuerte cotizaba a la par del dólar, y bastante por encima del franco francés, podemos concluir que durante la así llamada Organización Nacional la Argentina por primera vez contó con un conjunto de capitalistas que legítimamente podían calificarse como millonarios según patrones internacionales. De todas maneras, todavía faltaba bastante para alcanzar el momento en el que las palabras «argentino» y «rico» se vuelvan sinónimos en los salones de París, o que la riqueza argentina se consagre como la más prominente de Sudamérica. La clase alta chilena, por ejemplo, aún se ubicaba muy por encima de la porteña en términos de riqueza. Así lo indica, por ejemplo, el hecho de que para 1882 hubiese no menos de cuarenta chilenos con fortunas superiores a $\$ F$ 1.000.000. La posesión de una residencia como la que la viuda de Matías Cousiño edificó en Santiago en la década de 1870 a un costo cercano a los $\$$ F 2.000 .000 , y que sólo consumió el 15 por cien de su fortuna, estaba fuera del horizonte (y de las posibilidades) de los ricos de Buenos Aires ${ }^{29}$. Esta situación no se modificaría hasta los años del fin de siglo, momento en el cual la elite chilena comenzó a advertir que sus congéneres del otro lado de los Andes la habían dejado atrás en riqueza y esplendor ${ }^{30}$.

La información que estas sucesiones nos ofrece confirma la acentuación de la orientación rural de los negocios de la elite económica porteña. Sin embargo, este avance estuvo lejos de ser arrollador. De hecho, el peso de la inversión rural se ubica en niveles sólo ligeramente superiores a los que observamos para los inventarios del período 1853-64. Esta circunstancia no deja de llamar la atención, sobre todo porque nos hallamos en una etapa de fuerte expansión agraria, que dio lugar a importantes incrementos en el precio del suelo, que inevitablemente deben haberse visto reflejados en la estructura de los patrimonios. Finalmente, se advierte que ha crecido algo la importancia de las colocaciones bancarias. Este fenómeno sin duda nos habla de los progresos de la banca, cuyo desarrollo experimentó un salto cualitativo tras la caída de Rosas. Es de destacar, sin embargo, que la importancia de este ítem no es muy grande, y lo mismo puede decirse de la inversión en los nuevos instrumentos legales (acciones, papeles) que crecieron al calor de la moderni-

29 Bauer (1975), p. 205.

30 Correa Sutil (2004), pp. 212-27. 
zación institucional que la economía argentina sufrió en esos años. Al mismo tiempo, el hecho de que la propiedad urbana no haya disminuido su relevancia respecto a momentos previos es reveladora. Sugiere que los más poderosos capitalistas porteños (o, al menos, los de mayor edad entre ellos) siguieron percibiendo a la inversión inmobiliaria como un destino rendidor y seguro para colocar sus ahorros, al que parecen haber preferido por sobre otras formas más «modernas» de inversión. La veloz valorización que por entonces experimentaba el suelo urbano, que en algunos casos no fue inferior a la del suelo rural, sugiere que esta conducta no era absurda ${ }^{31}$.

Por último, giremos nuestra atención hacia los capitalistas con patrimonios inferiores a los $\$ F 750.000$. Estas fortunas, que oscilan entre los $\$ F 563.000$ y los $\$ F$ 119.000, alcanzan un promedio de $\$ F$ 328.454. Como en períodos anteriores, advertimos que los capitalistas de segundo rango que integran este grupo solían actuar preferentemente en un único campo de actividad. En esos años, el único patrimonio urbano de consideración es el de Lázaro Elortondo (que alcanzaba los \$F 228.300, el 67,8 por cien en inmuebles urbanos, y el resto en créditos y efectivo). En los restantes seis casos, las inversiones rurales predominan: Nicanor Miguens, Juan Antonio Cascallares, Anselmo Sáenz Valiente, José Otamendi, Pedro Alfaro y Felipe Arana eran todos ellos empresarios del agro, y sólo este último tenía inversiones urbanas de consideración, por encima del cuarto de su patrimonio total. El notable incremento de estas fortunas rurales (promedio \$F 348.481) respecto de las tasadas el período anterior (unas cinco veces) corrobora lo que ya hemos señalado sobre la acelerada expansión del sector agroexportador en esos años de «fiebre lanar». La información para los seis empresarios con inversiones predominantemente rústicas que se hallan en esta categoría es la siguiente:

CUADRO 9

CAPITALISTAS CON INVERSIONES PREDOMINANTEMENTE RURALES CON PATRIMONIOS INFERIORES A \$F $750.000(1865-75)(n=6)$

\begin{tabular}{|c|c|c|c|c|c|c|c|}
\hline $\begin{array}{c}\text { Propiedad } \\
\text { Urbana }\end{array}$ & $\begin{array}{c}\text { Chacras } \\
\text { y Quintas }\end{array}$ & $\begin{array}{c}\text { Prop. rural } \\
\text { empresas } \\
\text { agropec. }\end{array}$ & $\begin{array}{c}\text { Créditos } \\
\text { acciones, } \\
\text { activos } \\
\text { comerciales } \\
\text { industriales }\end{array}$ & $\begin{array}{c}\text { Depósitos } \\
\text { bancarios }\end{array}$ & Efectivo & Otros & $\begin{array}{c}\text { Promedio } \\
\text { patrimonio }\end{array}$ \\
\hline $20,1 \%$ & $5,9 \%$ & $69 \%$ & $0,6 \%$ & $1,1 \%$ & $1,8 \%$ & $0,7 \%$ & $\$ \mathrm{~F} 348.481$ \\
\hline
\end{tabular}

31 Hora (2005a), pp. 68-72. 
Como se advierte, el panorama que se exhibe en el cuadro 9 no presenta grandes sorpresas, y de hecho mantiene correspondencia con la imagen que surge del análisis de las fortunas rurales inferiores a $\$ F$ 200.000 tasadas entre 1853 y 1864 . Nos encontramos ante empresarios para los que la actividad rural representa el centro de sus negocios, y que en todo caso poseen algunas propiedades urbanas o suburbanas.

\section{EL PERFIL ECONÓMICO DE LA ELITE PORTEÑA: ALGUNAS CONCLUSIONES Y UNA PROPUESTA DE INTERPRETACIÓN}

Luego de este largo y por momentos tedioso recorrido podemos volver sobre los problemas más generales referidos a los rasgos que caracterizan a los grupos económicamente predominantes del Buenos Aires decimonónico. Teniendo en cuenta las limitaciones estadísticas del ejercicio que hemos ensayado, una primera consideración se refiere a la necesidad de tomar con recaudos las lecciones que de él se derivan. Antes que conclusiones definitivas, lo que este trabajo ofrece es, en primer lugar, un conjunto de sugerencias, basado en evidencias que necesitan mayor precisión y corroboración empírica.

Esta cautela no impide observar que la elite económica que cobró forma tras las conmociones de la independencia se caracteriza por un importante grado de renovación. Es indudable que algunas figuras que ya se encontraban en ascenso dentro de la elite colonial, como los Alzaga o los Anchorena, lograron afirmar sus posiciones en la cima de la sociedad porteña luego de la crisis del imperio español. Sin embargo, parte importante de los apellidos de renombre de la era borbónica desaparecieron del grupo de los verdaderamente ricos en el lapso de unas pocas décadas. Ninguno de los descendientes varones de los grandes mercaderes coloniales que dejaron fortunas por encima de los \$100.000 estudiados por Socolow tuvo una trayectoria económica lo suficientemente destacada como para mantener su lugar en los estratos más elevados de la sociedad porteña de mediados del siglo xIX. El hecho merece destacarse, puesto que los historiadores suelen mostrarse más propensos a enfatizar las permanencias que las fuerzas de cambio que afectan el mundo de los sectores económicamente preponderantes. La renovación de la elite no fue consecuencia solamente de las fuerzas que, en un régimen legal caracterizado por la partición igualitaria del patrimonio entre los herederos legítimos (habitualmente numerosos) de las familias de elite, tendían a fragmentar los grandes patrimonios coloniales. Las destrezas empresariales heredadas de la era mercantilista no parecen haber sido las más relevantes para mantener o acrecentar una fortuna en los tiempos que se abrieron tras la independencia. El nuevo escenario que 
comenzó a cobrar forma tras la apertura al comercio libre hizo posible la llegada a la cima de un numeroso contingente de nuevos hombres de fortuna que supieron sacar buen provecho de las oportunidades abiertas en las décadas que sucedieron a la emancipación. Todo sugiere, pues, que en esas décadas el proceso de renovación del sector más poderoso de la clase propietaria fue profundo.

La renovación de la elite estuvo estrechamente vinculada con la transformación que la economía de la región experimentó al calor de la apertura plena al mundo atlántico. Con la llegada del comercio libre, la producción ganadera para la exportación se convirtió en la actividad más dinámica de la economía de Buenos Aires. Desde entonces, muchos hombres de fortuna volcaron capital y energías en el campo, y se constituyeron en impulsores de la expansión de la producción rural en las praderas pampeanas. Esta constatación, sin embargo, no autoriza a concluir sin más que la producción agraria conformase la única fuente de ingresos o de inversión de los hombres más acaudalados de la región. La evidencia ofrecida en este estudio parece desmentir las imágenes, tradicionales o más recientes, que describen a la gran elite propietaria de las décadas que sucedieron a la Revolución de Mayo como un empresariado de base exclusivamente terrateniente. El análisis de los patrimonios de los mayores capitalistas de Buenos Aires de los años centrales del siglo pone de manifiesto un panorama más complejo, signado por una importante diversidad en lo que se refiere a los patrones de inversión y las fuentes de ingreso de este grupo. Entre ellos ocupan un lugar destacado la renta urbana y, en menor medida, los negocios comerciales y financieros. En algunos casos, y no precisamente de los menos relevantes, éstos se revelan de una importancia similar a los referidos a la tierra y la producción agropecuaria. Aun si concedemos que hacia el final de sus vidas algunos de los capitalistas que analizamos en este trabajo se deshicieron de parte del patrimonio productivo que poseían en el campo y se volcaron a invertir en la ciudad con mayor fuerza que en etapas previas de su ciclo vital, la imagen resultante está lejos de coincidir con la que describe a esta clase propietaria simplemente como una elite puramente terrateniente. Y los rasgos urbanos que hemos puesto de manifiesto se vuelven más acusados cuanto más alto miramos en la jerarquía de la riqueza.

A la luz de la evidencia ofrecida en este ensayo, el patrón de inversiones de los grandes capitalistas del medio siglo que sucedió a la independencia se revela más diversificado que el que era habitual en la etapa colonial tardía, cuando el capital mercantil constituía el componente dominante de los patrimonios de la elite de negocios, y las fortunas rurales ocupaban un lugar subalterno en la jerarquía de la riqueza rioplatense. Algo similar se advierte cuando se compara este patrón de inversiones con el que predominó en la etapa dorada de la economía de 
exportación argentina que comenzó a cobrar forma en la década de 1870. Durante el gran boom agropecuario argentino que comprende las décadas de tránsito del siglo XIX al XX, el peso de las inversiones agrarias en las fortunas que dejaron los mayores empresarios rurales - para entonces sin lugar a dudas los mayores empresarios del país-, rara vez se encontraba por debajo de los dos tercios de su patrimonio total ${ }^{32}$.

A esta altura, no resulta sencillo ofrecer una explicación convincente de los motivos que dieron forma al patrón de inversiones diversificado que caracteriza a las fortunas de los mayores empresarios que aquí hemos estudiado, que contrasta tanto con la situación previa como con la posterior. Cada caso individual sin duda reclama explicaciones específicas. Al mismo tiempo, el carácter generalizado de este fenómeno invita a ofrecer algún principio de explicación de orden más abarcativo.

En este sentido, puede argumentarse que la diversificación de activos constituyó una respuesta a las abruptas transformaciones y al horizonte de incertidumbre que dominaron a la economía rioplatense en el primer medio siglo de vida de la Argentina independiente. Esas décadas no pueden describirse como de ascenso sereno e ininterrumpido de la economía ganadera. Calamidades naturales (como la gran sequía de 1829-32) e instabilidad institucional (guerras civiles e internacionales, bloqueos del comercio exterior, expropiaciones, inflación e incertidumbre monetaria y legal) dieron forma a un patrón de desarrollo de la economía rural signado por intensas fluctuaciones. Y a pesar de la elevada rentabilidad de la producción ganadera en el largo plazo, la intensidad de los movimientos de precios y el carácter espasmódico, su expansión lo volvieron incierta como única fuente de ingresos, sobre todo en el corto plazo. Para adecuarse a las presiones de un escenario cambiante y riesgoso, los mayores capitalistas rioplatenses parecen haber apostado a invertir en un sector dinámico y en expansión, pero sin tornarse excesivamente dependientes de esta única fuente de ingresos. A diferencia de lo que sucedería entrada la segunda mitad del siglo, el hecho de que a lo largo de gran parte de este período el aumento del precio del suelo fuese todavía relativamente moderado limitó las expectativas de incremento patrimonial en el largo plazo que podían crearse en torno a la posesión de tierra; ello volvió a los capitalistas más propensos a buscar otras esferas más seguras donde invertir sus excedentes. Al igual que para otros empresarios latinoamericanos que actuaban en escenarios que ofrecían alta rentabilidad pero elevados riesgos (como los agiotistas que prestaban dinero al gobierno mexicano), la diversificación de inversiones constituyó un elemento central de la estrategia de negocios de los grandes

${ }^{32}$ Hora (2002b). 
propietarios rurales de Buenos Aires, orientado a limitar su exposición ante un contexto inestable ${ }^{33}$. Por este motivo, el costo de oportunidad y la tasa de beneficio sectorial no parecen las únicas variables a considerar a la hora de analizar sus decisiones de inversión. En rigor, hasta cierto punto los magnates porteños parecen haber diversificado sus fuentes de inversión no tanto para maximizar sus beneficios como para minimizar riesgos.

Ello era posible porque las oportunidades de negocios en la región no se limitaban a la actividad primaria para exportación. Como en su momento señaló Jonathan Brown, no siempre se toma en cuenta que la expansión ganadera que caracterizó a esas décadas tuvo un efecto positivo sobre otros sectores de actividad ${ }^{34}$. Si bien la economía bonaerense carecía de un sector secundario o terciario de envergadura, la expansión del ingreso rural otorgó un nuevo dinamismo a la economía en su conjunto. Durante ese período, la ciudad de Buenos Aires reafirmó su lugar como emporio mercantil, vinculado a la cuenca del Plata con el mercado mundial. Cuando la crisis de independencia quedó atrás, se hizo evidente que la ciudad comenzaba a experimentar un intenso proceso de crecimiento espacial y demográfico (mucho más veloz que el que entonces atravesaban otras ciudades latinoamericanas como Río de Janeiro o México), que expandió la demanda urbana de bienes de consumo y elevó sistemáticamente la renta del suelo ${ }^{35}$. No sorprende, pues, que muchos capitalistas urbanos que antes de 1810 habían hecho su fortuna en la esfera mercantil se resistieran a desplazar todos sus recursos hacia el campo. E incluso los individuos que surgieron como grandes empresarios dentro del sector rural luego de 1810, y que no reconocían lazos previos con otra actividad, en distintos momentos de su trayectoria se ocuparon de girar parte de su capital hacia otras esferas. Este patrón de inversiones nos está revelando que estos hombres percibían la colocación de capital en el sector rural como una inversión que entrañaba importantes riesgos, quizás muy propicia para escalar a gran velocidad los primeros peldaños en el camino hacia la riqueza, pero a cuyos avatares no convenía sobreexponerse de modo permanente. El hecho de que las fortunas más diversificadas fuesen también las más grandes indica que esta conducta era más habitual entre aquellos que contaban con mayores márgenes de maniobra para encarar estos cambios.

El escenario en el que se desenvolvieron los capitalistas de la era republicana temprana permitió esta diversificación patrimonial, pero también le fijó límites. La economía rioplatense de los primeros dos ter-

\footnotetext{
33 Tenembaum (1986), p. 92.

34 Brown (1979).

35 Hora (2005b), pp. 578-9.
} 
cios del siglo XIX carecía de grandes economías de escala y su tecnología era sencilla, lo que permitía mantener intereses simultáneos en distintas esferas. Sin embargo, las posibilidades de inversión parecen haberse visto constreñidas tanto por factores institucionales como de mercado. A diferencia de lo que entonces sucedía en economías más estables o más maduras, Buenos Aires carecía de un mercado de papeles y acciones que resultase atractivo para los capitalistas que buscaban dar seguridad a sus inversiones. A diferencia, por ejemplo, de los propietarios esclavistas de Estados Unidos, los capitalistas porteños no gozaban de la posibilidad de colocar parte de sus activos en papeles públicos que rendían un seguro 6 por cien anual ${ }^{36}$. El dominio del gran comercio de importación y exportación por mercaderes extranjeros suponía un obstáculo de otra índole a las propuestas de diversificación. En esta esfera, los mercaderes provenientes del Atlántico norte gozaban de ventajas (resultado de su acceso privilegiado al crédito externo y a contactos con los mercados de destino) que los nativos no podían igualar. Como han sugerido distintos autores, los mercaderes extranjeros debieron adaptar sus operaciones al contexto de incertidumbre que afectaba al intercambio mercantil en el Río de la Plata ${ }^{37}$. Pero los beneficios que resultaban de sus estrechos vínculos con las economías nordatlánticas y, en muchos casos, su relativa alienación respecto a la sociedad local y su inserción limitada en el tiempo en la economía rioplatense, parecen haber desestimulado a los integrantes de este grupo a fijar su riqueza de modo sistemático en bienes inmuebles urbanos o rurales (lo que se constata gracias a su conspicua ausencia de referencias a este tipo de activos tanto en las fuentes fiscales como en las sucesorias). Ello parece estar confirmando que este grupo constituía, como indican Gelman y Santilli, el segmento más especializado de la clase capitalista en la región ${ }^{38}$.

Estas constricciones sin duda condicionaron las oportunidades de inversión para los capitalistas nativos, limitando los terrenos en los que la diversificación resultaba posible o redituable. Factores singulares que no resulta sencillo ponderar al momento de generalizar, que remiten a la experiencia individual de cada capitalista (vinculados a su trayectoria previa, a sus destrezas específicas y su vocación por el riesgo) pueden ofrecer indicios sobre el énfasis particular con el que los propietarios de origen colonial, y los que se sumaron a ellos luego de 1810 , se dispusieron a incursionar en distintos terrenos de actividad: algunos mantuvieron una mayor presencia en el comercio y el préstamo, otros se volcaron más decididamente hacia los negocios rurales, otros apostaron en mayor

\footnotetext{
36 Scarborough (2003), p. 151.

37 Adelman (1999), p. 124; Irigoin (2000), p. 353.

38 Gelman y Santilli (2004).
} 
grado a la seguridad que ofrecía la renta urbana, etc. Sobre todos ellos, empero, pesaron las fuerzas que moldearon el escenario económico del período republicano temprano, invitándolos a dispersar sus activos, buscando combinar inversiones (en su mayoría rurales) de alta rentabilidad en el largo plazo con otras que garantizasen seguridad (dentro de las que predominaba la renta urbana). De acuerdo con estos razonamientos, pues, el sector más poderoso de la elite económica del medio siglo que sucedió a la ruptura con España puede describirse mejor como un empresariado que poseía un patrón de inversiones diversificado con una base rural muy dinámica y de creciente importancia, que como un empresariado exclusivamente terrateniente.

Las evidencias que presentamos en este trabajo ayudan a entender por qué la asociación entre gran riqueza y actividad rural, que resulta corriente en los estudios históricos sobre ese período, aún no había terminado de soldarse en el imaginario de los habitantes del Buenos Aires postindependiente. Ello se advierte, por ejemplo, en el uso todavía parcial de tal identificación en la retórica política de las décadas de 1820 y 1830. En esos años, las descripciones de la elite económica como una "aristocracia del dinero" de raíz urbana (como la muy conocida invectiva de Manuel Dorrego en los debates del Congreso de 1826 sobre la reforma de la ley electoral) eran habituales. E incluso un par de décadas más tarde, durante el largo gobierno de Juan Manuel de Rosas, esta situación no se había modificado radicalmente, como lo sugiere el hecho de que las clases populares rurales no parecen haber advertido que se hallaban ante un proceso de formación de una elite terrateniente ${ }^{39}$. Considerando estas circunstancias, no resulta casual que en la visión de la prensa antirrosista figuras como Tomás Manuel y Nicolás de Anchorena, a quienes solemos identificar entre los terratenientes más arquetípicos de ese período, no aparezcan retratados como propietarios rurales sino como burgueses urbanos ${ }^{40}$. Esta situación ayuda a entender la observación de ese agudo comentarista de la realidad de su tiempo que fue Lucio V. Mansilla, que en Una excursión a los indios ranqueles señaló que la riqueza en Buenos Aires se medía no en campos sino «en fincas», esto es, en inmuebles tanto rústicos como urbanos ${ }^{41}$.

En principio, puede resultar sorprendente comprobar que luego de dos o tres décadas de apertura comercial y expansión agraria, las principales fortunas de Buenos Aires y de la Argentina toda siguieran manteniendo importantes anclajes urbanos. Como ya señalamos, el incierto contexto en el que tuvo lugar el giro hacia la inversión agraria puede

\footnotetext{
39 Salvatore (2003).

40 Ferro (2003), p. 102.

${ }^{41}$ Mansilla (1993), p. 203.
} 
explicar la cautela con la que los grandes capitalistas se volcaron a invertir en el campo. Al mismo tiempo, algunas características que signaron a las empresas rurales de esta primera fase de expansión ganadera ayudan a entender esta peculiaridad. Las reducidas inversiones iniciales necesarias para poner en marcha una explotación ganadera de gran escala y, por sobre todas las cosas, el bajo costo de las instalaciones fijas, por largas décadas pusieron un techo al peso relativo de la tierra y las empresas agrarias en el conjunto de los patrimonios de la elite. En consecuencia, las empresas ganaderas funcionaron más como fuente de ganancias que como reserva de valor. Esas rústicas explotaciones rurales no admitían el tipo de conductas rentísticas con las que a veces se retrata a los estancieros del período. El proceso de valorización del suelo que ganó fuerza en la pampa hacia mediados de siglo comenzó a modificar esta situación, y fue recién entonces que las fortunas rurales (o mejor, el componente rural de las fortunas de la elite) comenzaron a dominar sin rivales la cúspide de la gran riqueza argentina. Fue este proceso el que, a la vez que elevaba a la clase propietaria rural argentina a una posición de preeminencia entre las elites latinoamericanas, constituía a la renta del suelo en una categoría clave para entender a ese grupo.

La acentuación de la vocación rural de la elite entrada la segunda mitad del siglo XIX, aun cuando en sí misma significativa, no implicó el abandono de otras formas de inversión. Aunque en niveles inferiores a los habituales en décadas previas, las colocaciones en propiedad urbana siguieron representando una porción considerable del patrimonio de los miembros más ricos de la clase propietaria. La persistencia de esta modalidad de inversión parece estar indicando que el sector rural no fue el único que experimentó el efecto positivo del crecimiento económico del medio siglo que sucedió a la independencia. El intenso proceso de valorización que el suelo urbano experimentó a lo largo del período que analizamos convirtió a la renta territorial en un poderoso mecanismo de succión de la riqueza social (por largo tiempo quizás más importante que la renta del suelo rural), y del que las clases propietarias sacaron buen provecho. Se advierte aquí un rasgo que pone de relieve cierto carácter arcaico (o parasitario) de los ricos de Buenos Aires. En el mismo sentido, no deja de llamar la atención la timidez de los capitalistas porteños a la hora de invertir en acciones, papeles y otras formas de riqueza que cobraron forma al calor de la modernización técnica y legal que la economía argentina experimentó luego de la caída de Rosas, que crearon nuevas oportunidades de lucro en sectores tales como ferrocarriles, banca y servicios públicos. De hecho, los elementos aquí reunidos sugieren que el porcentaje del patrimonio de los grandes capitalistas nativos colocados en papeles y acciones se mantuvo en niveles bien modestos, por debajo no sólo de una plaza mercantil de la envergadura 
de Río de Janeiro, sino también de una ciudad agraria de segundo orden como San Pablo ${ }^{42}$.

Pasado el umbral del medio siglo, la vocación rural de los hombres de fortuna de Buenos Aires se acentuó. Es probable que la creciente complejidad que la economía alcanzó en esas décadas, sumada un orden institucional más estable, hiciesen que las estrategias de diversificación de negocios que en décadas previas sirvieron para atemperar las bruscas oscilaciones de ingreso que caracterizaban al mundo económico local perdieran algo de su anterior atractivo. El rápido crecimiento que el sector de exportación experimentó en esos años, estimulado por un contexto institucional más favorable para la acumulación de capital y por una fase de expansión del mercado mundial para los productos de la pampa (que entonces comenzaron a ser liderados por la ganadería del ovino), seguramente acentuó el interés de muchos capitalistas por la inversión rural. Y aun cuando esa nueva etapa no estuvo exenta de crisis y retrocesos, en el último tercio del siglo el ritmo de crecimiento de la economía agraria se volvió a la vez más acelerado y menos fluctuante, y el atractivo de la tierra creció en su calidad tanto de recurso productivo como reserva de valor. Como se advierte en los patrimonios del fin de siglo, ello sentó las bases para la consolidación de un empresariado aún más especializado en la actividad rural, que cortó las amarras que lo ataban a otras formas de inversión de modo más acusado que en cualquier momento del pasado ${ }^{43}$.

\section{BIBLIOGRAFÍA}

Adelman, Jeremy (1999): Republic of Capital. Buenos Aires and the Legal Transformation of the Atlantic World. Stanford: Stanford University Press.

Amaral, Samuel (1988): The Rise of Capitalism on the Pampas. The Estancias of Buenos Aires, 1785-1870. Cambridge: Cambridge University Press.

BANZATO, Guillermo (2002): «Formación y gestión del patrimonio en los partidos de Chascomús, Ranchos y Monte, 1800-1880». Ponencia presentada en las XVIII Jornadas de Historia Económica, Asociación Argentina de Historia Económica, Mendoza.

BARBA, Fernando Enrique (1999): Aproximación al estudio de los precios y salarios en Buenos Aires desde fines del siglo XVIII hasta 1860. La Plata: Editorial de la Universidad Nacional de la Plata.

BAuER, Arnold (1975): Chilean Rural Society from the Spanish Conquest to 1930. Cambridge: Cambridge University Press.

BoorsteIn COUTURIER, Edith (2003): The Silver King: The Remarkable Life of the Count of Regla in Colonial Mexico. Albuquerque: University of New Mexico Press.

BRown, Jonathan (1976): «Dynamics and Autonomy of a Traditional Marketing System: Buenos Aires, 1810-1860». Hispanic American Historical Review, 56:4, pp. 605-29.

42 Cardoso de Mello (1990), p. 164; Frank (2005), p. 249.

43 Hora (2002a) 
- (1979): A Socioeconomic History of Argentina, 1776-1860. Cambridge: Cambridge University Press.

Cardoso de Mello, Zélia Maria (1990): Metamorfoses da riqueza. São Paulo, 18451895. São Paulo: Hucitec.

Correa Sutil, Sofía (2004): "El pensamiento en Chile en el siglo xx bajo la sombra de Portales», en O. Terán (coordinador): Ideas en el siglo. Intelectuales y cultura en el siglo XX latinoamericano. Buenos Aires: Siglo XXI, pp. 211-305.

Ferro, Gabriel (2003): Barbarie y Civilización. Sangre, monstruos y vampiros durante el segundo gobierno de Rosas (1835-1852), Tesis de Maestría en Investigación Histórica, Universidad de San Andrés.

FradKIN, Raúl (1997): «Tulio Halperin Donghi y la formación de la clase terrateniente porteña», en R. Hora y J. Trímboli (compiladores), Discutir Halperin. Siete ensayos sobre la contribución de Tulio Halperin Donghi a la historia argentina. Buenos Aires: El Cielo por Asalto, pp. 71-111.

FrANK, Zephir (2005): «Wealth Holding in Southeastern Brazil, 1815-1860». Hispanic American Historical Review, 85:2, pp. 223-257.

Garavaglia, Juan Carlos (1999a): Pastores y labradores de Buenos Aires. Una historia agraria de la campaña bonaerense, 1700-1830. Tandil-Sevilla-Buenos Aires: IEHS-Univ. Pablo de Olavide, Ediciones de la Flor.

- (1999b): «Patrones de inversión y "elite económica dominante”: los empresarios rurales en la pampa bonaerense a mediados del siglo XIX», en J. Gelman, J. C. Garavaglia y B. Zeberio (editores): Expansión capitalista y transformaciones regionales. Relaciones sociales y empresas agrarias en la Argentina del siglo XIX. Buenos Aires-Tandil: La Colmena-IEHS, pp. 121-143.

- (1999c): «Un siglo de estancias en la campaña de Buenos Aires, 1751-1853». Hispanic American Historical Review, 79:4, pp. 703-734.

GELMAN, Jorge (1996): De mercachifle a gran comerciante: los caminos del ascenso en el Río de la Plata Colonial. La Rábida: Universidad Internacional de Andalucía.

- (1998): Campesinos y estancieros. Una región del Río de la Plata a fines de la época colonial. Buenos Aires: Libros del Riel.

Gelman, Jorge, y SANTIlli, Daniel (2004): «Las elites económicas de Buenos Aires en la época de Rosas. Patrones de inversión, movilidad y fragmentación en tiempos de cambio». Prohistoria, VII:8, pp. 11-37.

Halperin Donghi, Tulio (1963): «La expansión ganadera en la campaña de Buenos Aires», Desarrollo Económico, vols. 1-2:9-10, pp. 57-100.

- (1972): Revolución y guerra. Formación de una élite dirigente en la Argentina criolla. Buenos Aires: Siglo XXI.

- (1995): "The Buenos Aires Landed Class and the Shape of Argentine Politics, 1820-1930», en E. Huber y F. Safford (editores), Agrarian Structure and Political Power. Landlord \& Peasant in the Making of Latin America. Londres y Pittsburg, University of Pittsburg Press, pp. 39-66.

Hora, Roy (2002a): Los terratenientes de la pampa argentina. Una historia social y política, 1860-1945. Buenos Aires: Siglo XXI.

- (2002b): «¿Landowning bourgeoisie or business bourgeoisie? On the peculiarities of the Argentine economic elite, 1880-1945». Journal of Latin American Studies, 34:III, pp. 587-623.

- (2003): "The making and evolution of the Argentine economic elite: the example of the Senillosas». Hispanic American Historical Review, 83:3, pp. 451-486.

- (2005a): «Del comercio a la tierra y más allá: los negocios de Juan José y 
Nicolás de Anchorena (1810-1856)». Desarrollo Económico, 44:176, pp. 567600 .

- (2005b): «Patrones de inversión y negocios en Buenos Aires en la primera mitad del siglo xix: el ejemplo de Tomás Manuel de Anchorena». Història Econômica \& Història de Empresas, 8:1, pp. 41-82.

IRIGOIN, María Alejandra (2000): «Inconvertible Paper Money, Inflation and Economic Performance in Early Nineteenth Century Argentina». Journal of Latin American Studies, 32:II, pp. 333-359.

Johnson, Lyman (1999): "The Frontier as an Arena of Social and Economic Change: Wealth Distribution in Nineteenth-Century Buenos Aires Province», en D. J. Guy y T. E. Sheridan (editores), Contested Grounds: Comparative Frontiers on the Northern and Southern Edges of the Spanish Empire, Tucson: University of Arizona Press, pp. 122-146.

MANSILLA, Lucio V. (1993; edición original 1870): Una excursión a los indios ranqueles. Buenos Aires: Espasa Calpe.

Mateo, José (1993): «Población y producción en un ecosistema agrario de la frontera del Salado (1815-1869)», en R. Mandrini y A. Reguera (compiladores), Huellas en la tierra. Indios, agricultores y hacendados en la pampa bonaerense, Tandil: IEHS, pp. 161-190.

Marichal, Carlos (1986): «Foreign Predominance among Overseas Traders in Nineteenth-Century Latin America: A Comment». Latin American Research Review XXI:3, pp. 145-151.

Mayo, Carlos (1991): «Landed but not Powerful: The Colonial Estancieros of Buenos Aires (1750-1810)». Hispanic American Historical Review, 71:4, pp. 761-779.

- (1995): Estancia y sociedad en la pampa, 1740-1820. Buenos Aires: Biblos.

Miguez, Eduardo José (2000): «El capitalismo y la polilla. Avances en los estudios de la economía y la sociedad rural pampeana, 1740-1850». Boletín del Instituto de Historia Argentina y Americana Dr. Emilio Ravignani, 21:1, pp. 123-133.

Platt, D. C. M. (1972): Latin America and British Trade, 1806-1914. Nueva York: Harper and Row.

- (1986): «Dependency in Nineteenth-Century Latin America: an historian objects». Latin American Research Review, XV:1, pp. 113-130.

Robinson, Karla (1979): «The Merchants of Post-Independence Buenos Aires», en W. S. Coker (editor), Hispanic-American Essays in Honor of Max Leon Moorhead. Pensacola: Perdido Bay Press, pp. 118-136.

SALVATORE, Ricardo (2003): Wandering Paysanos. State order and subaltern experience in Buenos Aires during the Rosas Era. Durham y Londres: Duke University Press.

SALVATORE, Ricardo, y NEwLAND, Carlos (2003): «Between independence and the golden age: The early Argentine economy», en G. Della Paolera y Alan M. Taylor, A New Economic History of Argentina. Cambridge: Cambridge University Press, pp. 19-45.

Scarborough, William Kauffman (2003): Masters of the Big Houses: Elite Slaveholders of the Mid-Nineteenth-Century South, Baton Rouge: Louisiana State University Press.

Socolow, Susan (1991): Los mercaderes de Buenos Aires: familia y comercio. Buenos Aires: De la Flor.

Tenembaum, Bárbara (1986): «Banqueros sin bancos: el papel de los agiotistas en México (1826-1854)», en C. Marichal y L. Ludlow (editores): Banca y poder en México (1800-1926), México: Grijalbo, pp. 75-97. 